\title{
PAHLAWAN DAN PENJAHAT DALAM VISI RETORIS PERSAUDARAAN ALUMNI 212 PADA REUNI AKBAR 2019
}

\author{
Elyan Nadian Zahara \\ Pascasarjana Ilmu Komunikasi Universitas Indonesia \\ Email : elyanadianzahara@gmail.com
}

\begin{abstract}
$T$ he purpose of this study is to explain who were the Hero and Villains contributed to rhetorical vision's legitimation and the shared meaning embraced in the Grand Reunion of Alumni Brotherhood (PA) 212 in 2019. Rhetorical vision is determined by the dominant character and symbolic cues embraced as shared meanings in a group. This study used qualitative approach, while the data was collected using virtual ethnography method and analyzed using Borman's Fantasy Theme's Analysis. From the results of the study it was found that the dominant character mentioned in the reunion as a hero was Habib Rizieq Shihab, while the characters named as criminals were those who were considered to have defamed Islam, such as Abu Janda, Ade Armando, Sukmawati Soekarno Putri and Viktor Laiskodat. The rhetorical vision carried out is Moslem's victory. The grand reunion was held as an effort to urge the government to be more assertive and responsive to contemporary issues faced by Muslims in Indonesia.
\end{abstract}

Keyword: Defend Islam, Symbolic cues, 212 reunion, Fantasy themes

\begin{abstract}
ABSTRAK
$\mathrm{P}$ enelitian ini bermaksud untuk menjelaskan siapa Pahlawan dan Penjahat yang menjadi bagian dari legitimasi visi retoris serta makna bersama yang dibagi dalam Reuni Akbar Persaudaraan Alumni (PA) 212 tahun 2019. Visi retoris ditentukan dari karakter dominan serta isyarat simbolis yang dibagi sebagai makna bersama dalam sebuah kelompok. Pendekatan yang digunakan dalam penelitian ini adalah pendekatan kualitatif dengan etnografi virtual sebagai metode pengumpulan data, serta Analisis Tema Fantasi Borman sebagai teknik analisis data. Dari hasil penelitian didapati bahwa karakter dominan yang disebutkan dalam reuni sebagai pahlawan adalah Habib Rizieq Shihab, sedangkan karakter yang disebutkan sebagai penjahat adalah mereka yang dianggap telah menistakan agama Islam, seperti Abu Janda, Ade Armando, Sukmawati Soekarno Putri dan Viktor Laiskodat. Visi retoris yang diusung adalah kemenangan umat Islam. Reuni Akbar diadakan sebagai upaya mendesak pemerintah agar lebih tegas dan responsif terhadap isuisu kontemporer yang dihadapi umat Islam di Indonesia.
\end{abstract}

Kata Kunci: bela Islam, isyarat simbolis, reuni 212, tema fantasi. 


\section{PENDAHULUAN}

Senin, 2 Desember 2019 menjadi peringatan tahun ketiga Aksi Bela Islam di Indonesia. Dalam peristiwa yang disebut sebagai Reuni Akbar 212 ini, ratusan ribu massa hadir di silang Monas, Jakarta, dari berbagai daerah di seluruh Indonesia (Yuliawati \& Fajri, 2019). Aksi Bela Islam yang dikomandoi oleh Front Pembela Islam, digelar pertama kali pada tanggal 14 Oktober 2016. Ribuan massa hadir di Masjid Istiqlal dan kemudian bergerak menuju halaman Balai Kota Jakarta (Aksi anti-Ahok diikuti ribuan orang serba putih, 2016). Aksi ini dipicu oleh penistaan agama yang didakwakan terhadap Basuki Tjahaja Purnama (Ahok). Saat itu, Ahok tersandung kasus terkait pidatonya pada kunjungan kerja di Pulau Pramuka, Kepulauan Seribu, pada 27 September 2016 saat masih menjabat sebagai Plt. Gubernur DKI Jakarta (https://www.bbc.com/indonesia/indonesia39853373). Karena tidak membuahkan hasil, pada tanggal 4 November 2016 digelar aksi Bela Islam Jilid II di depan Istana Presiden dengan tuntutan agar kasus Ahok diproses secara hukum. Tuntutan ini disetujui oleh Presiden Joko Widodo (Jokowi) dengan menetapkan Ahok sebagai tersangka penistaan agama pada tanggal 16 November 2016.

Ketidakpuasan terhadap perkembangan peristiwa kasus Ahok, pada tanggal 2 Desember 2016, massa kembali menggelar Aksi Bela Islam Jilid III dengan tuntutan agar Ahok ditangkap. Aksi yang diadakan di sekitar silang Monas, Jakarta disebutkan dihadiri oleh sekitar 7 juta orang. 2 Desember kemudian dijadikan simbol pergerakan 212 untuk memperingati peristiwa bersatunya umat Islam dari seluruh penjuru Indonesia untuk
Elyan Nadian Zahara

memperjuangkan hal yang sama. Masyarakat yang menghadiri acara ini menamakan diri Persaudaraan Alumni (PA) 212. Aksi Bela Islam masih terus dilanjutkan pada 11 Februari 2017, 21 Februari 2017, 31 Maret 2017 dan 5 Mei 2017 untuk mengawal proses hukum Ahok. Pada tanggal 9 Mei 2017, vonis dijatuhkan dan Ahok harus mendekam di Rumah Tahanan Mako Brimob Depok.

Memperingati tahun pertama dan kedua, reuni akbar kembali digelar di tempat yang sama. Tema tahun 2017 adalah: "Mensyukuri Nikmat Allah SWT dengan Merawat Energi Al Maidah 51 untuk Kebangkitan Umat Demi Kejayaan NKRI" (Sulistiyono, 2017), sedangkan tema tahun 2018 adalah: "Melacak Motif, Menimbang Implikasi Sosial Politik” (Hariyanto, 2018). Di tahun ketiga, reuni akbar kembali digelar dengan tema "Munajat dan Maulid Akbar, Reuni Mujahid 212". Berdasarkan keterangan dalam siaran pers-nya, panitia reuni mengimbau Persaudaraan Alumni 212 untuk hadir dalam acara tersebut (Haryadi, 2019).

Berbagai macam spekulasi hadir sehubungan dengan berlangsungnya serangkaian aksi bela Islam dan reuni akbar yang dimulai sejak tahun 2016. Pihak yang kontra berpendapat bahwa gerakan ini sangat kental akan muatan politis, terutama saat aksi tersebut mengusung Anies Baswedan sebagai calon gubernur DKI Jakarta di tahun 2017 dan Prabowo Subianto sebagai calon Presiden di tahun 2019. Di sisi lain, patut dipertimbangkan untuk melihat fenomena ini dari sudut pandang kelompok PA 212. Peneliti mengangkat peristiwa tersebut untuk diamati lebih lanjut menggunakan Teori Konvergensi Simbolis (TKS) yang digagas oleh Ernest Bormann. 
Pahlawan Dan Penjahat Dalam...hal. 50-65

Peneliti mendapati beberapa temuan terkait dengan penggunaan teori ini dalam beberapa penelitian terdahulu. Zanin, et.al (2016) menggunakan TKS untuk melihat tema fantasi dari tim rugbi perempuan, serta bagaimana tema fantasi tersebut tidak hanya membentuk konvergensi simbolis, namun juga divergensi kelompok. Penelitian Angeline (2016) menjabarkan tema fantasi serta visi retoris dari Gerakan Sosial Pengumpulan Satu Juta KTP oleh Teman Ahok. Patria (2019) menggunakan TKS untuk mencari tahu fantasi kelompok pendukung Prabowo dalam Pemilihan Presiden (Pilpres) 2019, sedangkan implementasi TKS dalam komunikasi organisasi Islam dijabarkan dalam penelitian Prisgunanto (2017). TKS juga digunakan oleh Abdullah dan Mubarak ( 2019) untuk meneliti strategi dakwah di kalangan remaja.

Dari penjabaran di atas, TKS sebagian besar digunakan untuk mengidentifikasi tema fantasi yang menjadi alasan kohesivitas kelompok. Fitur karakter dalam visi serta isyarat simbolis yang menjadi tanda dimulainya tema fantasi yang menjadi rangkaian pembentukan visi retoris belum menjadi bahasan tiga peneliti terdahulu, padahal kedua unsur tersebut berperan menentukan sikap kelompok. Selain itu, penelitian terdahulu juga belum membahas konvergensi simbolis dalam sebuah acara akbar suatu komunitas, sehingga peneliti tertarik untuk mengadopsi TKS dalam meneliti Komunitas PA 212 pada acara Reuni Akbar 2 Desember 2019 lalu. Berangkat dari poin-poin tersebut, yang akan dibahas dalam artikel ini adalah tema fantasi pada Reuni Akbar Komunitas PA 212; karakter penjahat dan pahlawan serta isyarat simbolis dominan yang menandai berlangsungnya rantai fantasi pada Reuni
Akbar Komunitas PA 212.

Selain sebagai sebuah tinjauan akademis, artikel ini bermaksud memberikan pemahaman dari sudut pandang obyek yang diteliti akan maksud dan substansi diadakannya kegiatan tersebut, mengingat framing media arus utama yang tidak begitu baik terhadap gerakan serupa beberapa waktu sebelumnya (Ibnus, 2019; Pradipta et al., 2018; Robbiy, 2018).

\section{TEORI KONVERGENSI SIMBOLIS}

Pakar ilmu komunikasi dari Minnesota University, Ernest G. Bormann, mengambil temuan Robert Bales mengenai konsep dramatisasi dan melakukan kajian yang lebih mendalam tentang dinamika dramatisasi pesan dalam suatu kelompok, yang menjadi cikal bakal Teori Konvergensi Simbolis (TKS). Prinsip utama teori ini adalah "berbagi fantasi kelompok, menciptakan konvergensi simbolis" (Griffin et al., 2019).

TKS memiliki tiga bagian struktur (Bormann, 1985). Bagian pertama berkaitan dengan identifikasi dan pengaturan bentuk dan pola komunikasi berulang yang menunjukkan hadirnya kesadaran kelompok. Bagian kedua terdiri dari penjabaran dari muncul, berlangsung dan hilangnya kesadaran kelompok dalam hal makna, motif, dan komunikasi dalam kelompok. Bagian ketiga adalah faktorfaktor yang menjelaskan alasan anggota kelompok berbagi fantasi. Dua bagian pertama dapat terlihat dari dokumentasi percakapan, namun bagian yang ketiga lebih sulit untuk diketahui. Tiga formulasi yang mungkin adalah psikodinamika individu dalam kelompok, kemampuan retorika saat berbagi fantasi, dan yang ketiga adalah 
hubungan antara individu dengan kelompok yang berbagi fantasi dengannya. Formulasi yang ketiga mengandung gagasan bahwa ketika orang berbagi fantasi, mereka membangun dan memiliki kecenderungan untuk dramatisasi tertentu.

\section{Dramatisasi Pesan}

Bormann (Griffin et al., 2019) mendapati bahwa membicarakan hal-hal di luar konteks, seperti membicarakan rencana akhir minggu sebagai bentuk dramatisasi pesan seringnya bermanfaat untuk kelompok. Griffin, dkk (2019) menyebut pesan yang didramatisasi sebagai interpretasi kreatif dari imajinasi akan ruang dan waktu di masa yang akan datang. Terdapat dua ciri pesan yang didramatisasi:

1. Berisikan bahasa yang merangsang imajinasi seperti permainan kata, gaya bahasa, analogi, anekdot, alegori naratif, cerita dan ekspresi gagasan kreatif lainnya. Dengan kata lain, bahasa pesan tersebut mampu menggambarkan waktu dan kejadian di luar konteks masa kini.

2. Gambaran pesan haruslah di luar konteks ruang dan waktu saat ini. Pesan berupa imajinasi akan kejadian di ruang dan waktu pada masa yang akan datang. Hal ini akan membantu pembicara dan juga pendengar untuk dapat keluar dari situasi yang membingungkan serta mengarahkan pada masa depan yang jelas.

\section{Rantai Fantasi}

Fantasi kerap diasosiasikan dengan cerita anak-anak, hasrat seksual ataupun hal yang tidak nyata, namun Bormann mendefinisikan fantasi sebagai pesan dramatisasi yang secara antusias diterima oleh seluruh anggota kelompok. Tidak semua pesan yang didramatisasi
Elyan Nadian Zahara

menimbulkan reaksi seperti itu. Dalam beberapa kasus, ditemukan anggota kelompok yang justru tidak sependapat. Ini berarti kegagalan dari pesan tersebut.

Fantasi menghubungkan aspek rasional dan irasional karena seorang komunikator dapat menggunakan pikiran kreatifnya untuk mengkonstruksi logika dalam pesan yang ia sampaikan. Jika makna yang terdapat dalam pesan yang didramatisasi berhasil, dapat menimbulkan ledakan simbolis dalam bentuk reaksi berantai, yang menyebabkan anggotaanggota bergabung dan menghidupkan kelompok (Bormann, 1985). Menurutnya tanda-tanda fantasi berantai, seperti tempo pembicaraan yang meningkat; anggota kelompok menjadi bersemangat, menyela satu sama lain, tersipu, tertawa serta melupakan kesadaran diri mereka; serta komunikasi verbal dan nonverbal yang menunjukkan partisipasi dalam drama.

TKS menekankan reaksi dalam kelompok terhadap sebuah pesan. Bormann berkata bahwa kita dapat melihat rantai fantasi melalui reaksi yang umum terhadap perumpamaan. Tanggapan dapat berupa kekehan, anggukan, persetujuan, atau kalimat lainnya. Sejauh ini, keberhasilan peneliti TKS dalam memprediksi kapan fantasi akan menyala dan memicu reaksi berantai tidaklah besar. Menurut mereka, peluang terjadinya ledakan fantasi salah satunya adalah saat kelompok dalam kondisi frustrasi atau ketika mereka menemui jalan buntu dalam upaya memecahkan masalah yang pelik. Peluang yang lebih besar juga mungkin terjadi apabila ada anggota kelompok dengan keterampilan retoris yang baik, namun tetap saja tidak ada jaminan kata-kata mereka akan berhasil menyulut rantai fantasi. Rantai fantasi seolah memiliki 
Pahlawan Dan Penjahat Dalam...hal. 50-65 aturan sendiri, namun begitu berhasil terbakar, akan mempersatukan kelompok di bawah payung tema fantasi.

\section{Tema Fantasi}

Tema fantasi menjadi unit analisis dasar teori yang mencerminkan budaya kelompok yang berusaha diidentifikasi oleh semua peneliti TKS. Tema fantasi menjadi sarana retoris untuk meyakinkan anggota kelompok yang ragu atau menentang (Griffin et al., 2019). Anggota kelompok dapat berbagi sejumlah fantasi dengan alur cerita, adegan, karakter, dan situasi yang sama. Jenis fantasi atau skenario ini terus diulang dengan pola yang sama (Bormann, 1985). Lebih lanjut disebutkan bahwa makna, emosi, motif dan tindakan kelompok terlihat dalam tema fantasi mereka.

Tema fantasi ditandai dengan isyarat simbolis, yaitu suatu tanda yang memicu anggota kelompok untuk bereaksi seperti saat pertama kali fantasi dibagikan. Isyarat simbolis dapat berupa sandi, gerakan nonverbal, frasa, slogan, lelucon, stiker bemper, atau cara sederhana lainnya untuk membangun kembali kekuatan fantasi bersama. Bormann menggunakan istilah tipe fantasi untuk menjelaskan isyarat simbolis yang sering digunakan.

\section{Konvergensi Simbolis: Persatuan dan Kohesivitas Kelompok}

Griffin, dkk (2019) menyebutkan konvergensi simbolis sebagai dua atau lebih simbol tertentu yang cenderung berdekatan, terkadang tumpang tindih, yang mempersatukan dan dapat menciptakan kohesivitas kelompok. Setelah sebuah kelompok mengalami konvergensi simbolis, Bormann menyarankan untuk mengenang kesadaran kelompok dengan nama dan sejarah yang tercatat (kisah) yang mengingatkan saat-saat ketika rantai fantasi berlangsung.

Para cendekiawan melihat serangkaian tema dan jenis fantasi terkait dengan berbagai jenis teks komunikasi. Bormann menciptakan istilah visi retoris untuk menunjuk "sebuah drama gabungan yang menyatukan satu kelompok besar orang ke dalam realitas simbolis yang sama." Kelompok tersebut disebut dengan istilah masyarakat retoris.

Sebagian besar penelitian yang dilakukan dengan menggunakan TKS bertujuan untuk menangkap visi dari masyarakat retoris dan bagaimana mereka menciptakan fantasi bersama mereka. Bormann dan rekan-rekannya mengembangkan prosedur yang disebut analisis tema fantasi untuk menemukan tema fantasi dan retoris visi yang telah dibuat.

\section{Analisis Tema Fantasi}

Analisis tema fantasi adalah jenis kritik retoris khusus yang dibangun di atas dua asumsi dasar. Pertama, manusia menciptakan realitas sosial mereka. Kedua, makna, motif, dan emosi seseorang dapat dilihat dalam retorika mereka. Seorang kritikus retoris menggunakan Analisis Tema Fantasi untuk mencari tema fantasi berulang dalam sebuah teks. Jika ditemukan, peneliti harus mencari tahu apakah fantasi bersama ini terjalin bersama menjadi visi retoris. Selain menggunakan konsep-konsep dasar TKS yang sudah dibahas, peneliti disarankan untuk mencari setidaknya empat fitur yang hadir dalam semua visi retoris (Littlejohn \& Foss, 2018):

1. Karakter, dapat berupa pahlawan,
penjahat atau pemain pendukung
lainnya;


2. Alur, berupa gerak atau perkembangan cerita;

3. Tempat, yaitu latar, termasuk lokasi, perlengkapan dan lingkungan sosial budaya.

4. Agen pemberi sanksi, berupa seseorang atau sesuatu yang melegitimasi visi retorika.

\section{METODOLOGI}

Dalam artikel ini, data utama/objek penelitian berupa video rekaman Siaran Langsung Reuni Akbar 212 dari kanal Youtube milik Kompas TV berdurasi tiga jam satu menit dan lima puluh tiga detik ( https://www.youtube.com/watch?v=O_QhO B-_iT4). Objek diteliti dengan menggunakan pendekatan kualitatif. Dari video tersebut, data dikumpulkan dengan menggunakan metode etnografi virtual. Christine Hine (2015) menjelaskan bahwa agar dapat lebih fokus pada aspek pengalaman dari etnografi dalam melakukan observasi secara virtual, gagasan akan etnografi yang mensyaratkan kehadiran peneliti perlu dikesampingkan. Neuman (2014), menyebutkan bahwa studi kualitatif memberi makna data, menerjemahkannya, atau membuatnya dimengerti. Peneliti menggunakan sudut pandang objek penelitian untuk mencari tahu bagaimana mereka melihat dunia dan mendefinisikan situasi. Peneliti memelajari arti peristiwa, perilaku, dan kegiatan bagi mereka, oleh karena itu, peneliti menggunakan paradigma interpretif.

Proses komunikasi dalam TKS melibatkan pesan dramatis, rantai fantasi, tema fantasi, tipe fantasi dan visi retoris. Data dikelompokkan sesuai tahap dalam TKS dan dianalisis dengan menggunakan
Elyan Nadian Zahara empat alat ukur penanda hadirnya visi retoris, yaitu adanya karakter yang dibentuk: pahlawan atau penjahat; alur pesan: konsistensi dengan visi retoris yang dibentuk; Scene: latar tempat dan waktu yang dapat meningkatkan perkembangan tema fantasi; dan agen pemberi sangsi: seseorang/institusi yang melegitimasi visi retoris yg dibentuk.

Analisis dimulai dengan menempatkan pesan dramatis dengan potensi rantai fantasi ke dalam himpunan data. Pesan-pesan ini yang menjadi unit analisis, yang memungkinkan pembatasan himpunan hanya untuk pesan dramatis yang memiliki potensi untuk dirangkaikan dalam sebuah kelompok yang menjadi tema fantasi (Lindlof \& Taylor, 2011). Himpunan yang sudah tersortir, terbagi atas dua kategori, tema fantasi berantai dan tema non-fantasi. Fantasi berantai diketahui dengan mengidentifikasi pesan dramatis yang diulang-ulang oleh anggota-anggota kelompok. Sebagai contoh, jika sebuah pesan dramatis diekspresikan dalam interaksi tatap muka dan kemudian diulang dan dirantai oleh anggota kelompok, urutan tersebut dapat diindikasikan sebagai rantai fantasi. Dalam contoh yang lain, untuk pesan dramatis yang diungkapkan, namun tidak menimbulkan sebuah rantai, dieliminasi dan tidak disertakan dalam analisis lebih lanjut. Contoh rincian deskripsi dan urutan pengkodean dapat dilihat pada tabel 1. Begitu rantai fantasi teridentifikasi, proses pengkodean yang lebih fokus dapat dimulai dengan mengelompokkan kode menjadi kategori yang lebih sesuai (Charmaz, 2006). Pengkodean melibatkan proses komparatif yang berulang di mana pesan dramatis yang merantai dibandingkan dengan yang lain (Kramer \& Crespy, 2011). Jika pesan 
Pahlawan Dan Penjahat Dalam...hal. 50-65 memiliki kesamaan dengan kode sebelumnya, pesan dimasukkan ke dalam kategori kode yang sama. Jika berbeda, dibuat kategori yang baru.

\section{HASIL DAN DISKUSI}

Berdasarkan langkah-langkah di atas, didapati empat kategori besar tema fantasi yang berlangsung pada Reuni Akbar 212.

Rantai fantasi, yang menjadi penanda hadirnya tema fantasi, dimulai dari dibagikannya pesan dramatis, diikuti isyarat simbolis dan kemudian rantai fantasi berlangsung. Empat tema fantasi tersebut dirangkum ke dalam tabel 1 sampai dengan tabel 4, disertai analisis sebagai berikut:

Tabel 1. Sampel Urutan Pengodean Tema Fantasi 1

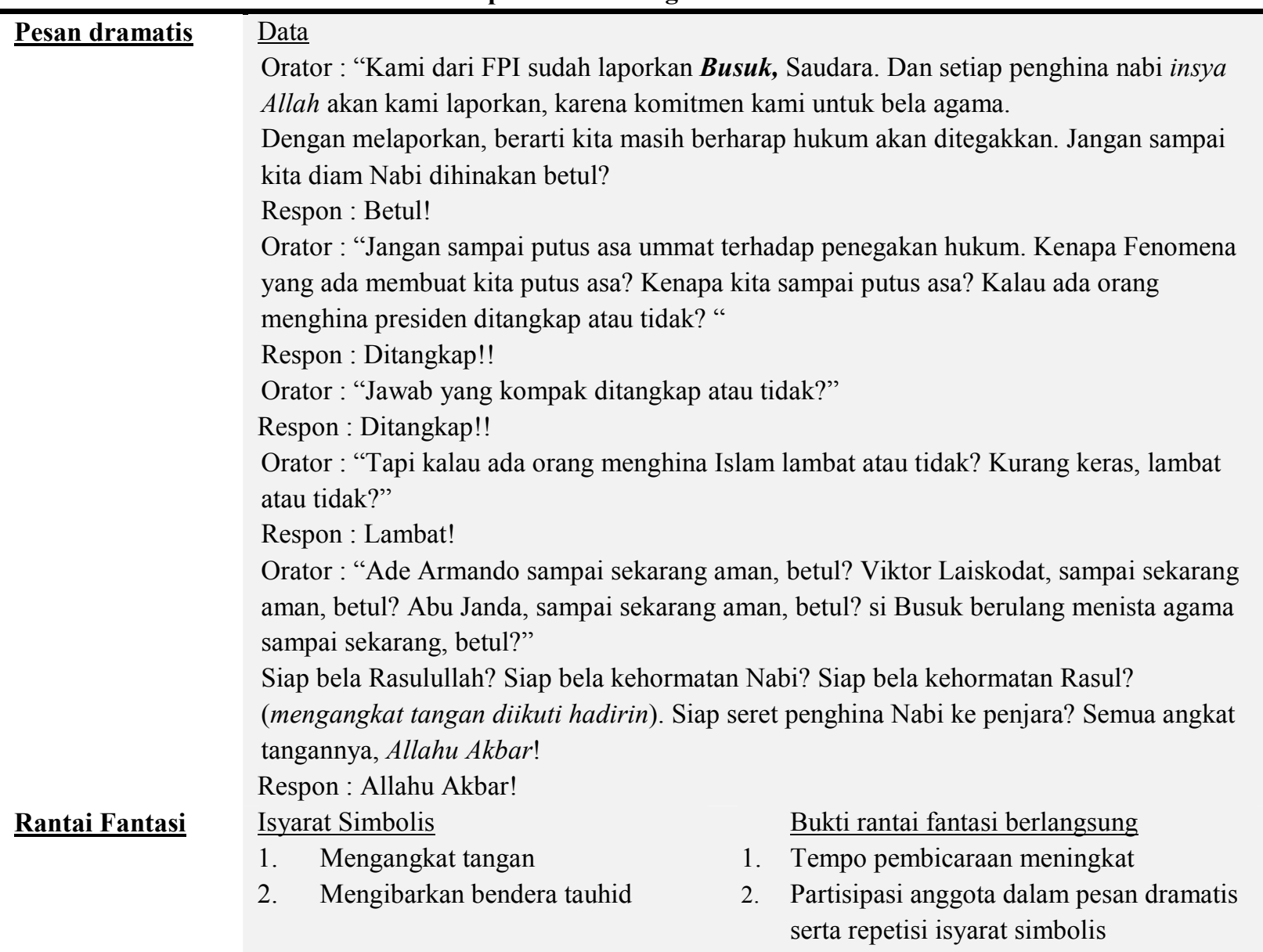

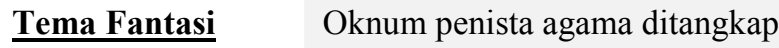

$\underline{\text { Visi retoris }}$ Kemenangan Umat Islam

Bormann (1985) mendefinisikan tema fantasi sebagai isi pesan yang didramatisasi hingga memicu rantai fantasi (the content of thedramatizing message that sparks the fantasy chain). Pada bagian ini, tema fantasi "oknum penista agama ditangkap"

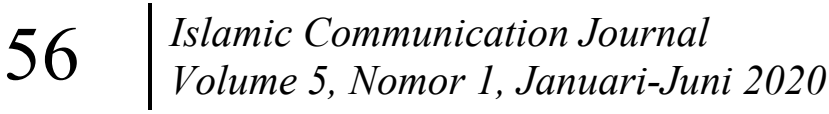

diidentifikasi berdasarkan pesan dramatis yang muncul berulang-ulang dan hadirnya isyarat simbolis berupa mengangkat tangan dan mengibarkan bendera tauhid pada saat Haikal Hassan memberikan orasi. Ini menjadi bagian pertama dari pembentukan 
Konvergensi Simbolik (KS) yang menunjukkan hadirnya kesadaran kelompok.

Bagian kedua KS berlangsung saat terjadi rantai fantasi yang diidentifikasi berdasarkan tempo pembicaraan yang meningkat dan partisipasi anggota dalam pesan dramatis (mengonfirmasi pernyataan Haikal Hassan), serta repetisi isyarat simbolis. Kemudian bagian akhir KS memuat penjelasan mengenai alasan anggota kelompok berbagi fantasi, yang ditegaskan melalui pernyataan berikut:

"Ade Armando sampai sekarang aman, betul? Viktor

Laiskodat, sampai sekarang aman, betul? Abu Janda, sampai sekarang aman, betul? si Busuk berulang menista agama sampai sekarang, betul?"

Dalam pernyataan itu juga, Ade Armando, Viktor Laiskodat, Abu Janda dan Busuk (Sukmawati Soekarno Putri) teridentifikasi sebagai karakter penjahat penista agama. Hal tersebut diketahui berdasarkan kalimat "berulang menista agama sampai sekarang, betul?”.

Diketahui sebelumnya, Ade Armando pernah dilaporkan pada tahun 2018 atas dugaan pidana penodaan agama terkait postingan Facebooknya yang berbunyi 'Azan tidak suci. Azan itu cuma panggilan untuk sholat. Sering tidak merdu. Jadi, biasa-biasa sajalah...'. Namun hingga saat ini belum ada titik terang soal kasus tersebut. Di tahun 2017, Ade juga pernah dilaporkan atas pelanggaran Undangundang Informasi dan Transaksi Elektronik (ITE) karena pernyataannya di Twitter pada tahun 2015 bahwa Allah bukan orang Arab.
Elyan Nadian Zahara Kasus ini sempat dihentikan karena kurangnya bukti (Permana, 2020).

Viktor Laiskodat dalam pidatonya di Kupang, menyerukan agar hadirin tidak memilih calon kepala daerah atau calon legislator dari partai-partai ekstremisme dan pro-khilafah, antara lain Partai Gerindra, Partai Demokrat, Partai Keadilan Sejahtera (PKS), dan Partai Amanat Nasional (PAN). Ia melanjutkan, jika khilafah berdiri, Negara Kesatuan Republik Indonesia (NKRI) tidak akan ada lagi. Bahkan, semua orang Indonesia akan diwajibkan melaksanakan salat dan gereja tidak boleh lagi berdiri. Viktor dilaporkan ke Mabes Polri oleh perwakilan Pemuda Muslim NTT, namun kasusnya tidak bisa dilanjutkan karena status Viktor saat berpidato adalah anggota dewan yang sedang melakukan reses sehingga memiliki imunitas. Polri mengarahkan kasus untuk diselesaikan di Majelis Kehormatan Dewan (Mustakim, 2017; Yamin, 2017).

Beberapa hari sebelum reuni berlangsung, Abu Janda alias Arya Permadi, mengeluarkan pernyataan bahwa teroris memiliki agama dan agamanya adalah Islam (Fahlevi, 2018). Pada saat reuni belum ada yang mengambil langkah hukum terkait pernyataan Abu Janda tersebut. Namun pada pertengahan Desember 2019, Ikatan Advokat Muslim Indonesia melaporkan Abu Janda ke Bareskrim POLRI atas delik penistaan agama. Pada bulan November 2018, Abu Janda juga pernah tersandung kasus serupa karena dianggap menghina syariat Islam lewat postingan pada akun Facebook-nya. Pada postingan tersebut, $\mathrm{Abu}$ Janda menyebut bendera tauhid adalah bendera

\section{Islamic Communication Journal \\ Volume 5, Nomor 1, Januari-Juni 2020


Pahlawan Dan Penjahat Dalam...hal. 50-65 teroris. Ia dilaporkan ke Bareskrim Polri oleh Majelis Taklim Al-Munawwir Bekasi, namun hingga kini kasusnya masih menggantung (Rahma, 2019).

Tidak jauh berbeda dengan yang lain, Sukmawati Soekarno Putri juga lebih dari satu kali dilaporkan atas dugaan penistaan agama. Pada tahun 2018, ia dilaporkan karena membandingkan kidung Ibu Indonesia dan suara azan serta konde dengan cadar dalam puisinya (Putra, 2018). Persoalan selesai karena Sukmawati menggelar jumpa pers untuk melakukan permintaan maaf terhadap umat muslim Indonesia. Di tahun 2019, Sukmawati kembali dilaporkan karena membandingkan Nabi Muhammad dengan Soekarno dalam hal jasa atas kemerdekaan Indonesia sebagai agen pemberi sanksi.
(Wildansyah, 2019).

Tahap selanjutnya adalah latar waktu, yang menegaskan visi retoris, yang tercantum dalam kalimat berikut: "Dan setiap penghina nabi insya Allah akan kami laporkan, karena komitmen kami untuk bela agama". Kata insya Allah mengisyaratkan perbuatan yang akan dilakukan di lain waktu jika Allah menghendaki.

Alur cerita dalam rangkaian visi retoris ini mengisahkan lemahnya penegakan hukum terhadap terduga penjahat penista agama, sehingga dibutuhkan persatuan dari PA 212 untuk membela agama dan mendesak penegakan hukum terhadap penjahat penista agama. Hal ini dilegitimasi oleh nilai-nilai agama yang diyakini oleh para pemuka agama

Tabel 2. Sampel Urutan Pengodean Tema Fantasi 2

\begin{tabular}{ll}
\hline Pesan dramatis & Data \\
& Orator : "Insya Allah kita sama-sama di dalam munajat ini bermunajat tentang \\
& kelangsungan Negara Kesatuan Republik Indonesia dan, kemaslahatan umat Islam dan \\
& umat beragama yang lain wabil khusus berdoa agar pencekalan, HR dapat diselesaikan dan \\
& insya Allah pada kesempatan yang akan datang sebelum reuni 2020, HR sudah berada di \\
& tengah-tengah kita. Setuju (intonasi naik)? " \\
& Respon : setujuuu \\
& Orator : "Kalau tidak dipulangkan kita tidak akan tinggalkan tempat ini, setuju (intonasi \\
& naik)? “ \\
Respon : setujuuu & Orator : Takbir! Allahu Akbar! \\
Respon: Allahu Akbar!
\end{tabular}

$\underline{\text { Rantai Fantasi }}$

$\underline{\text { Tema Fantasi }}$

$\underline{\text { Visi Retoris }}$
Isyarat Simbolis

Mengacungkan kepalan tangan ke atas

Habib Rizieq kembali ke Indonesia
Bukti rantai fantasi berlangsung

1. Tempo pembicaraan meningkat

2. Partisipasi anggota dalam pesan dramatis serta repetisi isyarat simbolis
Kembali ke Indonesia" diidentifikasi 
berdasarkan pesan dramatis yang dibagikan oleh Yusuf Martak, yang berulang-ulang meminta persetujuan dari para hadirin dan memastikan PA 212 untuk terus memperjuangkan kepulangan HRS. Tema fantasi ini sekaligus menjadi harapan dari PA 212.

Pesan dramatis kemudian diikuti isyarat simbolis berupa kepalan tangan yang diacungkan ke atas ketika mengucap takbir. Ini dilakukan baik oleh Yusuf Martak dan beberapa orang yang tersorot kamera di panggung. Pada titik ini, rantai fantasi berlangsung yang dibuktikan dengan tempo pembicaraan yang meningkat serta partisipasi hadirin. Dalam tema fantasi ini, Habib Rizieq diidentifikasi sebagai pahlawan dalam fantasi bersama kelompok.

Sebagaimana diketahui, Habib Rizieq meninggalkan Indonesia pada tanggal 26 April 2017 untuk umroh di Arab Saudi. Pada saat itu, sedianya Rizieq akan diperiksa aparat kepolisian terkait kasus 'baladacintarizieq'. Namun akhirnya pada Juni 2018, polisi menghentikan penyidikan kasus (Briantika, 2019). Bila tahun 2017 lalu surat pencegahan Rizieq dari Pemerintah RI terbit setelah
Elyan Nadian Zahara keberangkatannya ke Arab Saudi, Saat ini berdasarkan pernyataannya pada rekaman video yang diputar saat reuni, Rizieq menyebut akan dugaan adanya konspirasi pemerintah RI dalam mencegah kepulangannya ke Indonesia.

Jika melihat kembali sejarah PA 212, pembentukannya tidak lepas dari peran Habib Rizieq dan ormas FPI yang dipimpinnya. Ketidakhadiran Rizieq secara berturut-turut dalam tiga reuni akbar tersebab jarak. Oleh karena itu, segenap PA 212 prihatin dan merasakan kehilangan serta menuntut pembebasan Rizieq dari pengasingan. Hal ini tampak dalam pesan dramatis berupa orasi dari Yusuf Martak.

Wacana yang dibangun oleh PA 212 dalam reuni akbar adalah, bahwa terlepas dari simpang siur persoalan teknis keimigrasian yang dibicarakan oleh pejabat terkait, ada intervensi pemerintah yang membuat HRS tidak dapat pulang ke Indonesia. PA 212 menanggapi kasus ini sebagai sebuah persoalan serius dan mengangkatnya sebagai tema fantasi yang ditandai dengan terjadinya rantai fantasi.

Tabel 3. Sampel Urutan Pengodean Tema Fantasi 3

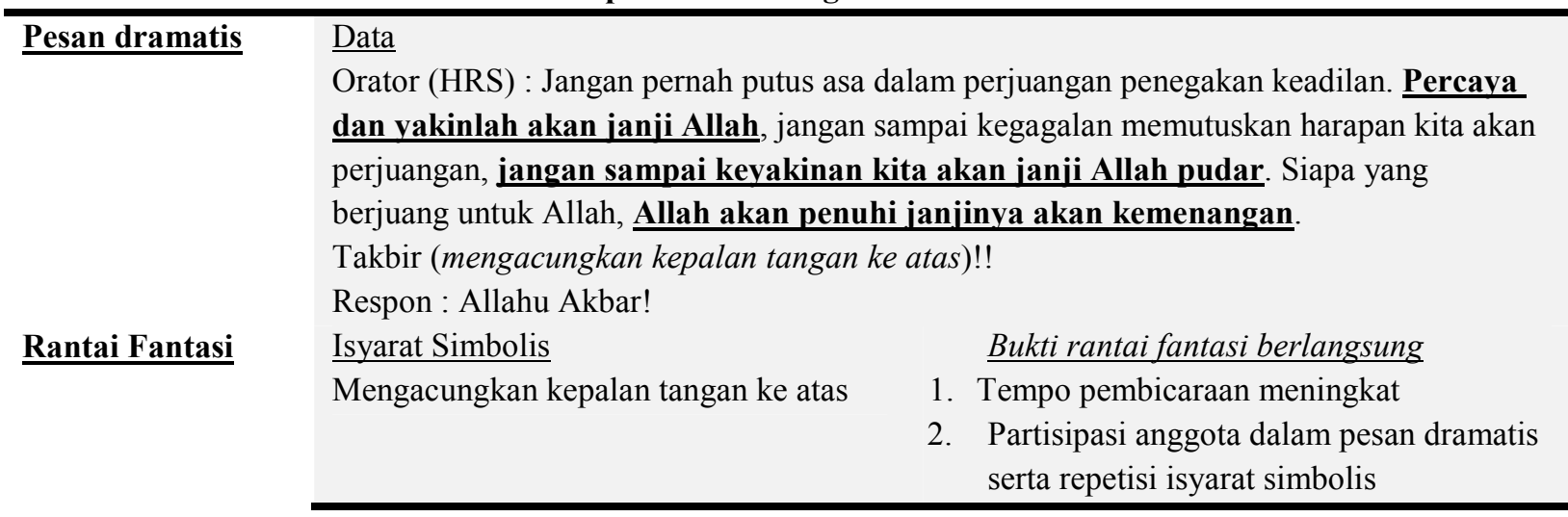


Tema Fantasi $\quad$ Percaya Janji Allah akan Kemenangan Perjuangan Islam

Visi retoris $\quad$ Kemenangan Umat Islam

Tema fantasi "Percaya Janji Allah akan Kemenangan Perjuangan Islam” diidentifikasi berdasarkan pesan dramatis yang muncul berulang-ulang, yang ditandai dengan berlangsungnya rantai fantasi disertai dengan isyarat Simbolis.

Sejak tahun 2016, maraknya penistaan agama oleh oknum-oknum tak bertanggung jawab dan lambannya gerak aparat negara dalam memproses hal tersebut menjadi salah satu latar belakang terbentuknya PA 212. Sejak terbentuk, tidak sedikit nada miring yang dilontarkan, labelisasi dari banyak tokoh masyarakat maupun pejabat negara, termasuk akan pelaksanaan Reuni Akbar setiap tanggal 2 Desember 2019 yang menyuarakan reaksi terhadap persoalan umat Islam Indonesia terkini. Namun demikian, Yusuf Martak dan Habib Rizieq mengingatkan untuk tidak berputus asa, melainkan mengingatkan akan rahmat dan berkah dari Allah bagi yang membela agamanya, dan mengimbau agar tidak berputus asa dari pertolongan Allah sebagaimana dicantumkan dalam Al-Quran.

\section{Tabel 4.Sampel Urutan Pengodean Tema Fantasi 4}

Pesan dramatis $\quad$ Orator (Ahmad Syafei) : "Allahu Akbar, Allahu Akbar, Allahu Akbar. Takbir (intonasi
meningkat)!"

Respon : Allahu Akbar!

Orator (Ahmad Syafei) : “MPUII adalah gerakan keumatan tanpa sekat organisasi, tanpa sekat kelompok, tanpa sekat partai politik, dan mazhab fiqih yang berupa jejaring yang diikat komitmen, dimotori oleh para ulama, tokoh, akademisi dan aktivis yang peduli akan masa depan umat islam dan kejayaan NKRI. “

"Mendambakan NKRI dikelola dengan konsisten dan konsekuen dengan pembukaan Undang-undang Dasar (UUD) 1945, sesuai dengan khitah perjuangan kemerdekaan Indonesia. Takbir! (intonasi meningkat)!"

Respon : Allahu Akbar!

Orator (Ahmad Syafei) : "Visi, terwujudnya kepemimpinan ulama, atau kepemimpinan yang direstui ulama warosatul anbiya dalam kehidupan berbangsa, bernegara berdasarkan ketuhanan YME sebagaimana dimaksud dalam pembukaan UUD 1945, sesuai dengan khitah perjuangan kemerdekaan Indonesia"

"Misi, mewujudkan pemimpin bangsa yang konsisten melaksanakan pembukaan UUD 1945, sesuai dengan khitah perjuangan kemerdekaan Indonesia.Takbir! (intonasi meningkat)!"

Respon : Allahu Akbar! 


\begin{tabular}{ll}
\hline Rantai Fantasi & $\underline{\text { Isyarat Simbolis }}$ \\
Mengacungkan kepalan tangan ke atas
\end{tabular}

Tema Fantasi $\quad$ NKRI Konsisten dan Konsekuen dengan Khitah Perjuangan Bangsa

Bukti rantai fantasi berlangsung

1. Tempo pembicaraan meningkat

2. Partisipasi anggota dalam pesan dramatis serta repetisi isyarat simbolis

$\underline{\text { Visi retoris }} \quad$ Kemenangan Umat Islam

Pesan dramatis "sesuai dengan khitoh perjuangan kemerdekaan bangsa" ini diulangi hingga tiga kali oleh Ahmad Syafei, Sekretaris dan Juru Bicara Majelis Permusyawaratan Umat Islam Indonesia. Pesan ini menyiratkan bahwa walaupun merupakan Negara dengan penduduk yang mayoritas beragama Islam, Pemerintahan saat ini belum konsisten dan konsekuen dengan cita-cita bangsa yang termaktub dalam Pembukaan UUD 1945, yaitu :

"melindungi segenap bangsa

Indonesia dan seluruh tumpah darah

Indonesia dan untuk memajukan

kesejahteraan umum, mencerdaskan

kehidupan bangsa, dan ikut

melaksanakan ketertiban dunia".

Pesan tersebut diikuti oleh rantai fantasi yang disertai takbir dan kepalan tangan yang diacungkan ke atas secara serempak baik oleh Ahmad Syafei maupun peserta reuni.

\section{Struktur TKS}

Dalam setiap tabel yang berisikan urutan pengodean dan kategorisasi tema fantasi, pesan dramatis mewakili bagian pertama dalam struktur TKS Bormann, yang mengidentifikasi pengaturan bentuk dan pola komunikasi berulang yang menunjukkan hadirnya kesadaran kelompok. Rantai fantasi dan isyarat simbolik yang menggambarkan penjabaran dari muncul, berlangsung dan hilangnya kesadaran kelompok dalam hal makna, motif, dan komunikasi dalam kelompok, menjadi bagian kedua dari struktur TKS. Dua bagian pertama dapat terlihat dari dokumentasi percakapan, namun bagian yang ketiga lebih sulit untuk diketahui (Bormann, 1985).

Bagian ketiga, yaitu faktor-faktor yang menjelaskan alasan anggota kelompok berbagi fantasi terlihat dalam video adalah kemampuan retorika anggota PA 212 saat berbagi fantasi, seperti Yusuf Martak, Ahmad Syafei, Haikal Hassan dan Habib Rizieq Shihab. Bormann menjelaskan bahwa bagian terakhir dari struktur TKS ini dapat berupa dinamika psikologis individu dalam kelompok, kemampuan retorika anggota saat berbagi fantasi, dan yang ketiga adalah hubungan antara individu dengan kelompok yang berbagi fantasi dengannya. 


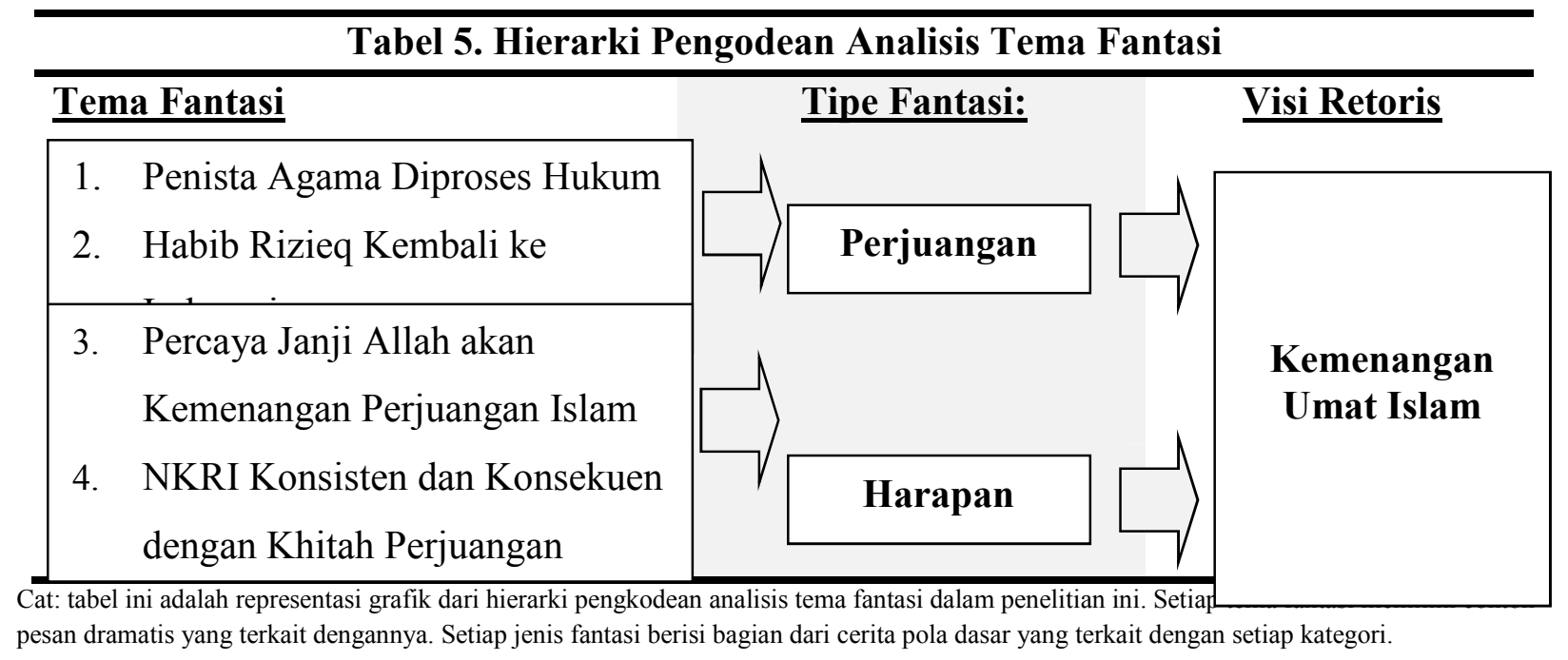

Dari keempat tema fantasi ini, tema fantasi pertama dan kedua bernada keras sedangkan tonasi tema fantasi ketiga dan keempat menukik turun dan berharap. PA 212 menunjukkan sikap kelompok secara eksplisit terhadap isu yang diangkat melalui pesanpesan dramatisnya. Makna bersama yang dibagikan di antara anggota kelompok adalah Reuni Akbar sebagai bentuk perjuangan agar penista agama diproses hukum yang menjadi upaya membela agama. Demikian pula dalam tema fantasi "Habib Rizieq Kembali ke Indonesia". Kelompok berbagi makna bahwa terkendalanya HRS kembali pulang ke Indonesia adalah bentuk pengasingan oleh negara, dan reuni akbar kali ini merupakan bentuk perjuangan dalam membela ulama serta agama.

Hal yang berbeda ditemukan dalam tema fantasi yang ketiga dan keempat, yang menyiratkan pengharapan bahwa upaya kelompok melalui reuni akbar kali ini mendatangkan rahmat dan berkah Allah, serta dapat mewujudkan NKRI yang sesuai dengan khitah perjuangan bangsa. Berdasarkan uraian di atas, tipe fantasi yang dapat ditarik adalah "perjuangan" dan "pengharapan".
Dalam rangkaian pembentukan KS ini, penjahat yang teridentifikasi adalah $\mathrm{Abu}$ Janda, Ade Armando, Sukmawati dan Viktor Laiskodat sedangkan pahlawannya adalah HRS. PA 212 mempersoalkan kejahatan berulang berupa penistaan agama yang mereka lakukan yang tidak ditanggapi serius oleh negara, sehingga membutuhkan pahlawan dari kalangan mereka untuk membela umat Islam. Hal ini menjadi alur cerita dari pembentukan KS. Kontestasi antara pahlawan dan penjahat ini memiliki satu tujuan tentunya, yaitu kemenangan umat Islam. Ini lah yang menjadi visi retoris dari KS PA 212, yang dilegitimasi oleh agen pemberi sanksi yaitu Allah SWT.

\section{KESIMPULAN}

Makna yang dibagi di antara para anggota PA 212 adalah bahwa pemerintah belum hadir untuk membela umat Islam dari para penghina agama, karenanya PA 212 sebagai persaudaraan Islam hadir sebagai perjuangan yang diberkahi Tuhan untuk membela agama, serta mengawal NKRI kembali kepada cita-cita perjuangan bangsa sebagaimana termaktub dalam pembukaan UUD 1945. Isyarat Simbolis dominan berupa kepalan tangan yang diacungkan ke udara secara serentak dan berulang-ulang disertai seruan takbir 
menjadi penanda bagi alumni 212 yang hadir untuk bereaksi dan membangun kembali fantasi bersama demi mewujudkan visi retoris kemenangan umat Islam. PA 212 mengusung Habib Rizieq sebagai tokoh pahlawan pembela agama, sedangkan Abu Janda, Ade Armando, Sukmawati dan Viktor Laiskodat di-sebutkan sebagai penjahat penista agama.

Reuni Akbar PA 212 dapat dilihat dari paradigma interpretif dengan menggunakan TKS. Namun perlu dipertimbangkan untuk melihat sisi lainnya dengan menggunakan Groupthink Theory. Benang merah yang menyatukan seluruh anggota PA 212 adalah keyakinan akan kebenaran agamanya dan dilegitimasi oleh Allah SWT yang menjadi agen yang berperan dalam menentukan visi retoris kelompok, sehingga idealnya perjuangan membela agama adalah sebuah panggilan yang sulit ditolak oleh umat Islam.

Namun demikian, Janis (Ruben \& Stewart, 2006) menyebutkan tiga faktor yang menjadi penanda hadirnya Groupthink di tengah kelompok, yaitu anggapan berlebihan terhadap moralitas dan kekuatan kelompok, pikiran yang sempit, serta tekanan untuk menjadi sama. Ini membuka celah untuk penelitian lebih lanjut dengan obyek penelitian yang sama namun dengan paradigma berbeda.

\section{DAFTAR PUSTAKA}

\section{[ LIVE] Situasi Terkini Reuni 212 di Monas}

Jakarta. (2019).

https:/www.youtube.com/watch?v=O_

QhOB-_iT4

Abdullah, M. Q., \& Dinul Fitrah Mubarak.

(2019). Strategi Dakwah Plural dalam

Merawat Pluralitas di Kalangan Remaja.

Anida (Aktualisasi Nuansa Ilmu

Dakwah), 19(2), 222-239.

https://doi.org/10.15575/anida.v19i2.758

9
Aksi anti-Ahok diikuti ribuan orang serba putih. (2016).

https://www.bbc.com/indonesia/indonesi a/2016/10/161014_indonesia_foto_aksi_ fpi_ahok

Angeline, M. (2016). Symbollic Convegence in a Social Movement: A Case of " Pengumpulan Satu Juta KTP” by Teman Ahok. Humaniora, 7(4), 535-543.

Bormann, E. G. (1985). A Communication Formulation. Journal of

Communication, 128-138.

Briantika, A. (2019). Rizieq Shihab, Antara Kabur atau Diasingkan. Tirto.Id. https://irto.id/rizieq-shihab-antarakabur-atau-diasingkan-emJD

Broom, C., \& Avanzino, S. (2010). The communication of community collaboration: When rhetorical visions collide. Communication Quarterly, 58(4), 480-501.

https://doi.org/10.1080/01463373.2010.5 25701

Charmaz, K. (2006). Constructing Grounded Theory. Sage Publications.

Fahlevi, F. (2018). Dianggap Hina Syariat Islam, Abu Janda Dilaporkan ke Polisi. Tribunnews.Com.

https://www.tribunnews.com/nasional/2 018/11/14/dianggap-hina-syariat-islamabu-janda-dilaporkan-ke-polisi

Griffin, E. A., Ledbetter, A., \& Sparks, G. G. (2019). A First Look at Communication Theory (10th ed.). McGraw-Hill Education.

Hariyanto, I. (2018). Bamukmin: Sejuta Bendera Tauhid akan Dikibarkan di Reuni Akbar 212. https://news.detik.com/berita/d4305138/bamukmin-sejuta-benderatauhid-akan-dikibarkan-di-reuni-akbar212

Haryadi, D. (2019). Aksi Mujahid 212 Ajak 
Pahlawan Dan Penjahat Dalam...hal. 50-65

Umat Islam Suarakan NKRI.

https://www.ayobandung.com/read/2019

/09/27/65162/aksi-mujahid-212-ajak-

umat-islam-suarakan-nkri

Hine, C. (2015). Ethnography for the

Internet: Embedded, Embodied, and

Everyday. Bloomsburry Academic.

Ibnus, N. (2019). The Representation of

Reunion 212 in Indonesian Online

Media. NOTION: Journal of Linguistics,

Literature, and Culture, 1(2), 68.

https://doi.org/10.12928/notion.v1i2.993

Littlejohn, S. W., \& Foss, K. A. (2018). Teori

Komunikasi. Jakarta: Salemba

Humanika. Salemba Humanika.

Mustakim, A. (2017). Pemuda Muslim NTT

Laporkan Viktor Laiskodat ke

Bareskrim. Detik.Com.

https://news.detik.com/berita/d-

3592352/pemuda-muslim-ntt-laporkan-

viktor-laiskodat-ke-bareskrim

Neuman, W. L. (2014). Social Research

Methods: Qualitative and Quantitative

Approaches.

https://doi.org/10.2307/3211488

Patria, L. (2019). Fantasi kelompok pendukung Prabowo di media sosial pada debat pemilihan presiden Indonesia 2019. 1(1), 47-58.

Permana, R. H. (2020). Laporan "FPI Preman" Ditolak, Ini Daftar Kasus

Pelaporan Ade Armando Lainnya.

Detik.Com.

https://news.detik.com/berita/d-

4894409/laporan-fpi-preman-ditolak-ini-

daftar-kasus-pelaporan-ade-armando-

lainnya/1

Pradipta, A. L., Nur Hidayah, N. W., Annisa

Haya, A. N., Ervani, C., \& Kristanto, D. (2018). Analisis Bingkai Pemberitaan Aksi Bela Islam 2 Desember 2016 (Aksi

212) Di Media Massa Bbc (Indonesia) \& Republika. Informasi, 48(1), 109. https://doi.org/10.21831/informasi.v48i1 .20203

Prisgunanto, I. (2017). DINAMIKA

BERBAGI TEMA FANTASI PADA

KOMUNIKASI ORGANISASI ISLAM

( Studi Konvergensi Simbolik Jamaah

Tabligh di Jakarta ) '. Lokarkarya

Nasional Dokumentasi Dan Informasi,.

http://pdii.lipi.go.id/loknas/index.php/co nference/loknas2017/paper/view/90/74

Putra, A. Y. (2018). Lagi, Sukmawati

Dilaporkan ke Polisi karena Puisi "Ibu

Indonesia.” Kompas.Com.

https://palembang.kompas.com/read/201

8/04/05/19040971/lagi-sukmawati-

dilaporkan-ke-polisi-karena-puisi-ibuindonesia

Rahma, A. (2019). Ikatan Advokat Muslim

Laporkan Abu Janda ke Bareskrim

Polri. Tempo.Co.

https://nasional.tempo.co/read/1282562/i

katan-advokat-muslim-laporkan-abujanda-ke-bareskrim-polri

Robbiy, S. R. (2018). Konstruksi Realitas

Republika Online dan Kompas.com

terhadap Pemberitaan Aksi 212.

Universitas Sebelas Maret.

Ruben, B. D., \& Stewart, L. P. (2006). Communication and Human Behavior (5th Editio). Pearson Education Limited.

Sidang Al Maidah: Dua tahun penjara untuk Ahok, langsung ditahan. (2017).

https://www.bbc.com/indonesia/indonesi a-39853373

Sulistiyono, S. T. (2017). Dimulai Pukul 03.00 WIB, Besok Reuni 212 Tetap

Digelar di Monas.

https://wartakota.tribunnews.com/2017/1

2/01/dimulai-pukul-0300-wib-besokreuni-212-tetap-digelar-di-monas

Wildansyah, S. (2019). Bandingkan Nabi Muhamad-Bung Karno, Sukmawati Dituduh Nista Agama. Detik.Com. 
https://news.detik.com/berita/d-

4787180/bandingkan-nabi-muhammad-

bung-karno-sukmawati-dituduh-nista-

agama/2

Yamin, M. (2017). Polisi Hentikan Kasus

Politikus Nasdem Viktor Laiskodat.

Sindonews.Com.

https://nasional.sindonews.com/berita/12

59393/13/polisi-hentikan-kasus-

politikus-nasdem-viktor-laiskodat

Yuliawati, L., \& Fajri, R. (2019). Soal

Jumlah Peserta Reuni 212, Ini Kata

Slamet Maarif.

https://www.vivanews.com/berita/metro/

22191-soal-jumlah-peserta-reuni-212-

ini-kata-slamet-

maarif?medium=autonext 